\title{
Process Competence and Expert Knowledge: Educational and Psychological Counseling Service vis-a- vis kindergartens and schools
}

\author{
Liv Heidi Mjelve ${ }^{1^{*}}$ \\ ${ }^{1}$ University of Oslo
}

\begin{abstract}
:
This study aims to develop knowledge of essential counseling competencies in the Educational Psychological Counseling Service (EPCS). Through semi-structured interviews with six counselors, the essential competencies of those who counsel teachers and parents are identified and discussed. Five main categories of competencies are proposed in response to the research question: What counseling competencies are considered essential during the counseling process? The results emphasize the importance of the counseling alliance, the counselor's awareness, the counselor's competencies in challenging and confronting the client, the counselor's subject knowledge and enhancement of the client's ownership of the proposed solution. Three of the categories (the counseling alliance, awareness and challenging/confronting) constitute counselors' process competence. The two remaining categories (subject knowledge and ownership) constitute counselors' expert knowledge. Conclusions: Process competence is heavily emphasized as essential for EPCS counselors and process competence and expert knowledge might be seen as two sides of the same coin.
\end{abstract}

Keywords: alliance; awareness; counseling; counseling competency; counseling relationship; kindergarten; school; ownership

\footnotetext{
* Principal contact:

Liv Heidi Mjelve

Department of Special Needs Education, University of Oslo

Tel.: +4722858131

E-mail: I.h.mjelve@isp.uio.no
} 


\section{Introduction}

Children and youth with special needs in kindergarten and school are a diverse group with different assistance and facilitation needs; however, the need for counseling appears to be common. In Norway, the Educational and Psychological Counseling Service (EPCS) is mandated to provide such help. EPCS is a legally required Service in each municipality in Norway and this Service has two main tasks: to support kindergarten and schools in developing relevant competencies and to ensure that expert assessments are prepared, as required by law (Act of Education, 1998). Expert assessments determine the special education service that children receive in kindergartens and schools. The EPCS has thus a dual role, both towards individuals and towards kindergarten and school systems. Counseling is a central way for EPCS of working with both individuals and systems. A high quality kindergarten/school system is for the best for all children including children and youth with special needs (Cameron, Kovac, \& Tveit, 2011; Hustad et al, 2013). Through counseling, kindergarten and schools are supported in developing relevant competencies for working with these children. Counseling is thus a core task of EPCS (Hustad, Strøm \& Strømsvik, 2013) and this fact serves as a basis for the current project, i.e., learning what competencies are essential to conduct a counseling process. The results of an extensive survey revealed the EPCS possesses very strong expertise in multiple themes/subjects but that the staff must develop competencies with respect to closer interaction with teachers, preventative work and early intervention (ibid.). Counseling teachers is one central/main way to interact closer with teachers and is also suitable as preventative work and early intervention. The latter includes also parents as a target group for counseling. Hustad et al (2013) concludes that counselors in EPCS need to have their counseling skills increased. This paper examines the important role of EPCS staff as counselors and their skills in conducting the counseling process.

The question of what high quality counseling competencies are in educational contexts is a complex question. A Norwegian study concludes among other things that counselors and consultees understand counseling quality both simple and complicated (Bjørndal, 2011). In the simple way counseling is seen as a clear, stable phenomenon that can be evaluated objectively and with certainty. The complex way emphasizes subjectivity and uncertainty in evaluating quality and sees counseling as a multifaceted and complex phenomenon (ibid.). This current study is based on a complex understanding of counseling. To explore what competencies are needed to conduct such a complex phenomenon is thus important. Parents' experiences of participation in counseling programs developed for parents of children with disabilities have been explored (Haugstvedt, GraffIversen, Bukholm, Haugli, \& Hallberg, 2013). The following outcomes was documented to be significantly improved through their (parents) participation in such programs: being motivated to communicate, describing oneself using new words, being inspired to experience one's own emotions, being more present and taking new steps (ibid). The main finding was that parents emphasized improvements in their abilities to handle situations through enhanced self-understanding; they described subjective processes of awareness and self-reflection. These finding implies that counselors in educational settings should be able to support such subjective and complex outcomes. This is also in accordance with an understanding of counseling as a complex phenomenon.

In general, much of the counseling literature emphasizes the counseling relationship as essential for outcome (eg Egan, 2014; Gelso, Williams \& Fretz, 2014; Lassen, 2014; Author, 2014; Rogers, C. R., Kirschenbaum, H., \& Henderson, V. L., 1990). Findings of research in related fields such as psychotherapy and supervision in psychotherapeutic contexts shows that relationships play a key role in positive client outcomes (Bordin, 1994; Orlinsky, Rønnestad, \& Willutzki, 2004; Råbu, Halvorsen, \& Haavind, 2011; Watkins, 1997). Råbu et al. (2011) showed how a detrimental relationship between therapist and client can be improved through a consideration of three 
significant factors: the identification and recognition of conflicts, the client's ability to disagree with the therapist, and the treatment of the client's problems in a playful and exploratory manner. Identification and recognition of conflicts involves awareness and clients' ability to disagree involves trust. Thus, a counseling relationship that includes awareness and trust is viewed as significant in this study.

Relationship is defined as the feelings and attitudes that counselors and clients have towards one another and the manner in which they are expressed (Gelso and Hayes, 1998). This is a simple and general definition that includes both clients' factors and factors associated with the therapist (Gelso et al., 2014). The latter has been studied by Rønnestad and Orlinsky (2005) and they propose that well-developed interpersonal skills by therapists are the key ingredients of healing involvement in psychotherapeutic work. Healing involvement is the goal of therapist development, which is also essential for generating a positive client outcome. Well developed interpersonal skills include responsive personal presence, empathy, and the ability to feel and communicate genuine concerns for others. In addition to strong interpersonal skills, other highly desirable qualities are mentioned by Rønnestad and Orlinsky (2005) as intellectual strength, curiosity and flexibility, and openness to new experiences.

Alliance is understood as one essential component of a counseling relationship (Gelso et al, 2014). The significance of alliance in psychotherapy has been well documented (Bedi, Davis, \& Williams, 2005; Flückiger, Del Re, Wampold, Symonds, \& Horvath, 2012; Horvath \& Bedi, 2002; Horvath, Del Re, Flückiger, \& Symonds, 2011). Orlinsky, Grawe, and Parks (1994) found that the strongest link between the process and outcomes is the therapeutic alliance. The research on psychotherapeutic outcome is extensive and the relationship between process and outcome is complex. However, working alliance has in the last decades been empirically investigated perhaps more than any other construct (Gelso et al., 2014). Working alliance consists of three parts, according to Bordin (1979): the emotional bond that forms between the participants, agreement of the counselor and clients on the goals of counseling and the tasks of the work. Geslo et al (2014) propose that there is a reciprocal causal relationship between alliance and the three dimensions discussed by Bordin; the alliance is strengthened by the emotional bond and agreement on the goals and tasks.

In supervision of psychotherapy the significance of alliance is also documented (Ladany \& Inman, 2012). It is also suggested that working alliance is of importance in supervision in educational settings (Bjørndal, 2016). A review of 18 published studies was conducted to identify the effects of various factors on supervision (Wheeler \& Richards, 2007). One of the central findings was that supervisees could be described as gaining self-awareness, a finding that suggests that counselors should support processes that foster growth of self-awareness.

These findings concerns psychotherapeutic contexts and a main question then is whether these findings can be transferred to counseling teachers and parents in educational settings - a very different counseling context. This context is different because the EPCS is legally required to help children who are referred to it (Act of Law, 1998). Its counselors are expected to exhibit strong competence in relevant subjects (such as child development, difficulties and needs, learning, kindergarten and school) and to disseminate their knowledge to teachers and parents to ensure that referred children are helped in a professional way that the EPCS seeks to guarantee. The purpose of the current study is to develop knowledge of the essential competencies needed to provide counseling from EPCS to teachers and parents in educational contexts. Thus, the research question is as follows: What counseling competencies are considered essential during the counseling process? In this paper, the counseling process refers to work performed in counseling sessions and through dialogue between counselors and clients. Clients include teachers and parents of students with 
special needs and will be used in the paper as a term to describe the one being counseled. To describe competence, the terms "essential", "significant" and "important" are used interchangeably in this study. Essential counseling competency means thus essential, significant and/or important competencies for the counseling outcome, experienced by the counselors.

Various definitions of competence have been proposed. Fuller (2006) distinguishes between formal and manifested competence, where formal competence is competence achieved through education, and manifested competence is the ability to meet demands in a particular context and/or complete a task successfully. Cognitive and non-cognitive dimensions are emphasized in the latter (Rychen, 2009). Counseling competence includes knowledge, skills, attitudes and values (Falender \& Shafranske, 2004), with cognitive and non-cognitive dimensions involved. This study is based on these definitions of competence, which is further understood as a relational phenomenon. A counselor's competence both affects and is affected by the counseling relationship. Counseling in educational contexts often involves three or more participants: counselor, teacher, student and/or parents. As a result, there are several sets of relationships involved - a challenging complexity. Counselors' competence is thus understood as overall and integrated professional abilities (Kaslow et al., 2004).

Humanistic counseling perspectives (Egan, 2014; Rogers, 1990) and gestalt theory are used as theoretical fundaments in this study. In gestalt theory, which is based in existentialism, phenomenology, gestalt psychology and field theory, contact and relational aspects in a counseling encounter are emphasized as essential (Gilbert \& Evans, 2000; Perls, Hefferline, \& Goodman, 1994; Yontef \& Bar-Yoseph, 2008).

\section{Method}

In this study, six qualitative interviews were conducted. The study design was inductive, descriptive and exploratory. Interviews were conducted over a period of four months at the participants' workplaces. Each interview lasted approximately 60 minutes (from 52 minutes to 69 minutes). The interview design was a combination of open and semi-structured; the interviews were structured around several themes and were otherwise developed in dialogue with each counselor, consistent with Kvale and Brinkmann's (2009) recommendations. Themes were elaborated around what the counselors emphasize in the counseling process and what competencies they experience as important. The researcher was a participant and instrument (Gold \& Zahm, 2008). The researcher's theoretical knowledge of and experience in counseling were incorporated into the interviews. However, the researcher endeavored to have an open mind and not let her own agenda get in the way of free flow of information, as recommended by Corbin \& Strauss (2008).

\section{Selection Criteria and Sample}

Strategic criteria (Dalen, 2004) were used to select participants to interview. One criterion was that participants were educated as special needs education counselors and not as psychologists. In Norway, there are several groups of professionals working as EPCS counselors, including pedagogues and special education teachers, psychologists, and social workers. The researcher sought the opinions of pedagogues because of their double role as both expert in the field of special needs and process counselor. Their five years of education (a master's in special needs education) involves four and a half years with special needs education subjects and only half a year of education and training in counseling. They are therefore special teachers themselves. Extensive experience (more than five years) was another criterion because I wanted the perspectives of experienced counselors. Finally, participants had to be counselors in ordinary kindergarten and schools as well as special schools, and 
they had to counsel parents and teachers. (In Norway, most children with special needs are included in ordinary kindergartens and schools, and some attend special schools.) Rather than predetermining the number of participants, I had initially intended to use a saturation threshold to determine how many people to interview. However, after interviewing 6 counselors the complex topic was not fully saturated and I was unsure if saturation would even be possible. I decided to analyze the data that I had collected from the 6 counselors, which I present here. The participants were recruited through the researcher's own collegial network; colleagues in different services were asked if they knew counselors who might be potential candidates. The researcher contacted the candidates by mail. The participants consisted of female counselors, aged 40-60 years. They were all special needs education counselors in the EPCS and had worked as counselors for more than 15 years. They worked in two different counties; four were from a county of 100,000 residents, and two were from a county of 50,000 residents. Two worked as counselors for kindergartens; three worked for ordinary schools; and one worked for a special school.

\section{Data Analyses}

The interviews were recorded, transcribed in NVivo10, a software program designed for qualitative studies and analyzed from a phenomenological, hermeneutic perspective. A phenomenological hermeneutic perspective implies studying phenomena as they are experienced by the participants, including the participants' thoughts and reflections about their experiences (Kvale \& Brinkmann, 2009). An examination of participants' thoughts and experiences in their ordinary, everyday work, was conducted. Through the open interview design and inductive analysis, their experiences were explored. A thematic analysis (Lindseth \& Norberg, 2004) was used to identify and formulate themes. The analyses were performed by the researcher in three phases in a hermeneutic, cyclic back-andforth process between the parts and the whole (Kvale \& Brinkmann, 2009). In phase one, the text was divided into meaning units, with the meaning units then condensed into nodes/themes in NVivo10. Some themes that were irrelevant to the research question were excluded at this point. Themes consisting of essential dimensions of counseling (such as emotions and confidentiality) and competencies (such as inquiring, wondering and challenging) appeared in the data. The next step (phase two) involved abstracting these themes into sub-themes. In phase three, these sub-themes were assembled into five main categories and analyzed using humanistic counseling theories, including gestalt theory (like Egan, 2014; Perls et al, 1994; Rogers et al, 1990; Yontef \& Bar-Yoseph, 2008) and the broad understanding of competence (Falender \& Shafranske, 2004; Rychen, 2009). Thus, three levels were employed in the analyses: descriptive, thematic and analytic (Richards, 2009). By conducting thematic analyses, the researcher hoped to remain sensitive to the participants' voices while benefitting from various theoretical perspectives. The analysis was discussed with other researchers during the process of analysis in separate meetings. Through referring and quoting parts of the interviews, the categories and themes were discussed and elaborated. The following terms are used to describe the different levels in the analysis (when the data were "boiled down"): category, main theme, theme, and sub-theme.

Member checking and triangulation are recommended as means of maximizing trustworthiness in phenomenological studies (Hays \& Wood, 2011). Member checking of the results was conducted in two ways: during the interviews and by mail following the analysis. Member checking during the interviews was conducted by continuously checking my interpretations; a strategy of reformulating the participants' utterances and checking that their meanings were correctly understood was employed. Member checking following the analysis was conducted by mail by asking participants whether they recognized the categories/sub-categories. All participants recognized and approved of the categories and subcategories developed. Direct quotations from the interviews are otherwise used in this paper to demonstrate the participants' utterances. The triangulation included discussion 
with other researchers during the research process regarding the study design, the method and the analysis (investigator triangulation). The Norwegian rules of ethics in science (NESH, 2006) were followed by obtaining informed consent and ensuring anonymity and confidentiality.

\section{Results}

What counseling competencies are considered essential during the counseling process? Serving to answer to this research question, the following five main categories emerged in the analysis: (a) alliance, (b) awareness, (c) challenging and confronting, (d) proposals for educational action and (e) ownership of solutions. Quotations are used in presenting the findings; because the interviews were conducted in Norwegian, I have translated these quotations. Some quotations may fall under several categories; I had to determine which theme each quotation best illustrated.

\section{Alliance}

The results show that the participants emphasized parts of the alliance as a central pre-condition in establishing a counseling relationship, and three sub-themes were stressed: trust, self-confidence and acknowledgement and praise. The idea of alliance entails more than these three sub-themes, but since these sub-themes all are central components in alliance, the main category is called alliance. Trust was emphasized in different ways. Referring to parents' vulnerability in using a public service for the first time, one counselor noted, "It is essential to establish trust in the relationship with the parents of preschool children; in cases where I am the first counselor who they meet, confidence is important to not lose them." Patience and adequate time were underscored as important factors in such cases. Equality was emphasized as an ideal: "Counselors must strive for equality in the relationship, and the goal with equality is to make teachers/parents feel safe enough to go deeper into sensitive themes." The counselor's self-confidence was emphasized as follows: "If you are confident in your work, it is easier to be curious and brave in the counseling". The hard work involved in developing self-confidence was also noted: "It is important to have self-confidence; it is only now, after ten years, that I feel like a qualified counselor". Facilitating the client's self-confidence was also underscored; a counselor in a special school referred to what she often told teachers: "You have enough knowledge to do your work; there is no need for a psychologist to perform these student dialogues". Acknowledgement and praise was the third sub-theme stressed; three ways of acknowledging and praising clients were emphasized. Mirroring was mentioned as one method: "I use a simple method: quoting the client". Signaling understanding of the client was another method mentioned: "I have to acknowledge his or her unique feelings and experiences". The third method noted involved mentioning a teacher's positive skills when observing him/her: "It is positive when you do it like 'this'... and you do 'this' many times".

\section{Awareness}

The findings revealed two sub-themes related to the phenomenon of awareness: the counselor's awareness of his/her thoughts and feelings and the counselor's awareness of the client. These two sub-themes include various strategies related to awareness, like disclosure of counselor's private/personal experiences and addressing client's feelings. Awareness is however used as the main category because awareness seems to be an essential factor underlying e.g. self-disclosure and addressing client's feelings.

The first sub-theme, the counselor's awareness of his/her thoughts and feelings, was emphasized in various ways. Some participants emphasized that not only identifying, but also using counselors' personal experiences plays an important role in the counseling process. One counselor referred to this role as follows: "I remember very well how important it was not to get too much 
information at once [when her own child was seriously ill]; this experience makes me extra sensitive to parents in similar situations". Others emphasized the importance of not using their own experiences: "If you open up with your own experiences and feelings, you can mess it up". The importance of maintaining adequate distance and not getting emotionally involved was also underscored. One counselor explained that "it is possible to maintain the required meta-perspective in the counseling process; a counselor should not get angry and/or irritated during the sessions". If anger or irritation should arise, it should be hidden. In relation to the second sub-theme, the counselor's awareness of the client, participants mentioned active listening as an essential skill. In this case, curiosity exemplified active listening: "I can use my curiosity towards any client, no matter who he or she is". Interpretations of clients were referred to as sensitive interventions; these interpretations must be formulated with care, especially when emotions are involved: "It is essential to be sensitive to how open parents are able to be about their sorrow". Several participants found addressing clients' feelings in sessions challenging; knowing the appropriate time to address clients' emotions was difficult. One participant discussed how to respond when clients become emotional: "I usually think that, e.g., parents' tears in sessions are not meant for me; they are most likely private. If someone is crying, I try to be present, signaling respect by asking if they need a break". Participants mentioned being able to handle parents' feelings in the counseling process as an essential competency.

\section{Challenging and Confronting}

The ability to challenge and confront clients was also highlighted as an important competency: "When a client denies that something is difficult when he actually experiences it as difficult, I have to confront him by pointing out this contradiction". In this specific case, the counselor had her own opinion about the teacher (the client) because she had observed his difficulty in the classroom. She found confronting the teacher when he gave contradictory messages in the counseling session entirely relevant. Participants also mentioned that questioning clients' decisions and/or solutions was important. One participant challenged a client by saying, "What will happen if you do like this or that instead?"

\section{Proposals for Educational Action / Advices}

Two important sub-themes related to this main theme were revealed: the counselor's subject/content knowledge and humility regarding clients' perspective/solutions. These sub-themes are central dimensions by counselors' proposals for educational actions; counselors' subject knowledge is the base of the given advices, also humility regarding clients' perspective. One participant noted that "a counselor has to know a lot about school, education questions, children, children's development-these are the core issues that we have to know a lot about". Another participant emphasized the importance of considering the client's proposed solutions, "It is important to remember that my solution is not always the best; it is essential to be humble and to consider the client's perspective". The participants mentioned open dialogue about different solutions as an important counseling skill/competency.

\section{Ownership of the Solutions}

The counselors emphasized the significance of the client's ownership of the defined solutions. One counselor explained, "My basic idea is that I have to use enough time to make sure that the clients/parents really understand the solutions we agree on". However, some participants mentioned that ensuring ownership was difficult: "Ownership for the clients is the most difficult part-I don't know how to make it [happen]". Ownership is important for change, according to several counselors. One counselor discussed the importance of trust in relation to change: "It is essential to make the 
clients believe in change". The counselors thus view ownership as the most important process, but they also find it to be particularly difficult to achieve.

These results (the five main categories) can be grouped into two main themes: the counselor's process competence and the counselor's role as an expert. The counselor's process competence includes three categories: the alliance, awareness and challenging and confronting. These three categories all represent different aspects of the counseling process and is thus grouped as a main theme: counselors process competence. The counselor's role as an expert involves the two remaining categories: proposals for educational action and the ownership of solutions. These categories both relate to the counselor's subject knowledge-the dissemination and receipt of said knowledge. These two aspects concern the counselor's role as expert.

\section{Discussion}

The exploration of professional practitioners' experiences offers promising possibilities for understanding counseling competencies in educational settings. The goal of investigating this relatively unexplored field was to develop knowledge about practicing counselors' experiences. For multiple reasons, counselors' process competencies and expert knowledge are particularly relevant for counselors in educational settings. For instance, the law requires that EPCS employees are experts (Act of Education, 1998); thus, there is an implied challenge in managing the dual role of both expert and process counselor. Another reason involves the education of pedagogues as counselors; most of the education of counselors in EPCS is related to the development of expert knowledge. This fact (that a major part of the education of counselors in EPCS is related to different kinds of subject knowledge) entails a gap that most likely leads to difficulties in managing their dual role. The investigation of these two aspects might be informative and useful for practicing professionals in the EPCS and other settings and for the education of special needs education counselors.

\section{Process Competence}

The findings of this study support the notion of the counseling alliance as a significant factor in the counseling process. This finding is in line with research on psychotherapy (Bedi et al., 2005; Flückiger et al., 2012; Horvath et al., 2011; Horvath \& Bedi, 2002) and supervision (Ladany \& Inman, 2012) of psychotherapy; the participants highlighted the counseling relationship alliance as an essential component of a special needs education context. To ensure such an alliance, trust was emphasized, and having adequate time and being patient were highlighted as important factors in building trust, according to the participants. However, building trust is a complex process; there are no straightforward ways to facilitate trust (Simon, 2009). A trusting relationship is a mutual process; it involves more than a counselor's patience and allotment of adequate time. However, this complexity was not discussed by the participants in this study.

The present study found that building clients' self-confidence to ensure an alliance is essential, which is in line with the research of Haugstvedt et al. (2013), who concluded that parents who participated in counseling programs felt inspired to take new steps. Self-confidence is likely a central factor in taking new steps. Thus, one might ask how to build a client's self-confidence or inspire a client to take new steps. According to participants in this study, praise and acknowledgement may be one answer to these questions. Humanistic counseling theories suggest that praise and acknowledgement might be offered in two ways: technically and/or attitudinally (Schibbye, 2012). The participants in this study noted that both these ways of offering praise are relevant. However, Schibbye (2012) suggests that an attitude of praise and acknowledgement is preferred in counseling to ensure equality, although counselors from the EPCS also highlight the importance of a technical 
approach to praise and acknowledgment. Their experiences with heavy workloads and too many tasks/cases might explain this finding, as technical praise may be easier to convey than an attitude of praise.

The current study's finding of self-confidence as essential to the counseling alliance refers not only the client's self-confidence but also the counselor's self-confidence. The counselors' extensive experience was highlighted as being central to their self-confidence; they felt that they had much more to offer after many years as counselors compared with what they could have offered at the beginning of their counseling careers. This finding is in line with Dewey's ideas about "learning by doing" and Lewin's model of the experiential learning process (Kolb, 1984); through practical work as counselors, they gain experience and, in turn, self-confidence. These counselors have only six months of education/training in counseling, which might affect how confident they feel at the beginning of their careers compared with later on, after years of practical work experience.

All these factors (building trust, building clients' self-confidence by praise and acknowledgement, and counselors' self-confidence) are essential for building alliance and are important to the emotional bond (Bordin, 1979) between a counselor and a client. However, according to Bordin (ibid) the idea of working alliance consists of three parts, the emotional bond in the counseling relationship and agreement on tasks and goals for the counseling process. The findings in this current study is thus only in line with one of the three parts. Agreement of the counselor and client on the tasks and/or the goals is not specifically mentioned by the counselors. In this respect the findings are only partly consistent with Bordin's working alliance.

Importantly, participants viewed awareness as an essential counseling competency and stressed the double focus of awareness: counselors' awareness of clients and counselors' awareness of their own thoughts and feelings. Cognitive and non-cognitive functions are included in both zones of awareness; according to the findings, awareness of clients implies attentiveness, openness and sensitivity to clients' emotional states. Counselors' awareness of their own thoughts and feelings also involves cognitive and non-cognitive elements. This broad understanding of awareness as a counseling competency implies complexity and brings together the various definitions of competence, emphasizing cognitive and non-cognitive dimensions (Fuller, 2006; Rychen, 2009).

Counselors' awareness of clients is at the core of counselors being able to handle clients' feelings. One of the findings in this study is related to this, that counselors must be competent in managing clients' feelings; in particular, participants highlighted the importance of being able to handle expressions of emotion, such as crying, by clients during counseling sessions. However, most participants believed that parents' tears were understood to be private and should not be addressed and explored in counseling sessions; a respectful response might involve offering the client a break or waiting before continuing the session. The results indicate that a counselor's task is to avoid addressing and exploring a client's tears during counseling sessions in special needs education contexts. This finding conflicts with the research of Haugstvedt et al. (2013), who found that one essential outcome of counseling, according to parents, is that they feel supported and are inspired to experience their emotions. In addition, this finding differs from those of Bedi et al. (2005), who showed that clients appreciated sharing their feelings and thoughts. This finding is also not consistent with the humanistic counseling literature, which argues that sharing feelings is an essential counseling competency (Egan, 2014; Gelso, Williams, \& Fretz, 2014). In counseling in special needs education, one factor may explain the discrepancies between the findings of the current study and those of other research and counseling theories. This factor applies to cases in which teachers are clients; teachers should receive help in their professional roles, not in their personal lives. In some cases, this admittedly unwritten professional rule may lead to less focus on a deep exploration 
of emotional matters and other long-term processes; such counseling occurs within an educational setting and differs from personal psychotherapy. Given the educational context of the counseling process, participants' recommendations not to explore clients' tears in counseling sessions is more understandable.

Counselors' awareness of their own thoughts and feelings is found to play an essential role, which is in line with research reporting that counselors' personalities and personal lives influence clients (Nissen-Lie, Havik, Høglend, Monsen, \& Rønnestad, 2013; Nordcross \& Lambert, 2011). However, while some participants in my study considered this type of awareness beneficial, others considered it a threat; the results were clearly mixed on this issue. The counselors who responded positively argued that sharing their own experiences was beneficial to clients. This finding supports the results of a study by Bedi et al. (2005), who found that clients are appreciative when counselors share their personal experiences. In contrast, skeptical counselors viewed bringing their own emotions to bear during counseling sessions as a threat; they wanted to concentrate on the clients instead of themselves.

The ability to challenge and confront clients was highlighted as an important counseling skill. Counselors stressed that confronting and challenging clients should be done with sensitivity and care and should be in the clients' best interests. This finding resonates with the humanistic theory of Egan (2014), who emphasizes the importance of counselors' abilities to challenge and confront clients to reveal clients' blind spots. The results also agree with the research of Råbu et al. (2011), who point to the importance of the client's ability to disagree with the therapist and the identification of conflicts in the counseling relationship; challenging and confronting can lead to such disagreements. The results are also in line with research that underscores the importance, from the client's perspective, of being challenged; parents who participated in a counseling program stressed that being challenged was helpful because it increased their self-awareness and self-reflection (Haugstvedt et al., 2013).

\section{Expert Knowledge}

Counselors from the EPCS have a formal role as experts (Act of Education, 1998); these counselors should have subject knowledge about children, development, disabilities, school systems and assessment. The findings of this study support the formal requirements of the EPCS; the counselors' dissemination of their subject knowledge is emphasized. Counselors in the EPCS consider themselves to have good/high subject knowledge (Hustad et al., 2013). An important question, however, remains: how can this knowledge be disseminated? The current study finds that humility regarding clients' perspectives is essential in the dissemination of counselors' subject knowledge. Humility involves cognitive and non-cognitive aspects and cannot be operationalized through simple concrete actions. Humility is an attitude that is similar to respect. What does being an expert with a humble, respectful attitude mean? Two aspects are involved: first, trusting one's own knowledge and, second, being humble/respectful towards clients' perspectives (for example, their experiences, knowledge, feelings and attitudes). The latter aspect accords with humanistic counseling theories (Gelso et al., 2014). However, how to manage both aspects was less elaborated upon in this research, although it is still of great relevance for counseling in special needs education contexts. This complexity is emphasized in this study and thus contributes to knowledge of essential competencies in special needs education counseling.

The client's ownership of solutions was highlighted as particularly significant. Other studies (Author, 2012, 2014) support this finding; without ownership, there are few or no positive outcomes. The term "introjection" is useful in elaborating the ownership phenomenon. An introjection is a 
process of uncritically "taking in" ideas, thoughts, feelings and attitudes from others without considering them and making them one's own (Perls, Hefferline, \& Goodman, 1994). Therefore, ownership is the opposite of introjection: considering and evaluating ideas of others - "taking in" some and discarding others. Such ownership is viewed as essential, although it is notably difficult to guarantee, creating a dilemma: EPCS counselors feel helpless in attempting to ensure one of the most essential aspects of counseling. Ownership concerns clients' integration of counselors' expert knowledge. However, supporting clients in their integration of this knowledge requires that counselors possess process competencies. Thus, according to the findings of this study, a central factor in counselors' process competencies may be beyond their control.

\section{Limitations of the Present Study}

The open design of this study is mainly beneficial, but it may also have some disadvantages. The open design entails that topics brought "to the table" by participants were followed up and elaborated upon; the participants were not directly asked about other counseling competencies. As a result of this strategy, important information may have been lost. Another limitation concerns validation of the findings. Other researchers did not analyze the data based on a specific structure; the findings were discussed with them. Consequently, a possible bias must be taken into account. The number of participants may also be seen as a limitation; more participants may have generated broader results. The six counselors provided, on the other hand, a considerable amount of information, and the data were experienced as saturated. However, the counselors' similar work settings may explain this saturation; the two services (EPCS) are located in similar municipalities (e.g., populations characterized by similar social conditions). Another limitation concerns that process competence is studied by interviews and not complemented by observations. Studying counselors' actions e.g. by using video observation could have revealed counselors' inherent competence. Another limitation may also be that only counselors were participants and not clients.

\section{Conclusions}

The two aspects, process competence and expert knowledge were explored as equals in this study. The research question regarding what counseling competencies are essential is answered by the five main categories that correspond to process competence and expert knowledge. Three categories fall under process competence, and two fall under expert knowledge. The results reveal that the participants emphasized process competence more strongly than expert knowledge. Differing accounts may explain this finding. For instance, process competence might be seen as more essential than expert knowledge. Additionally, expert knowledge might be viewed as an obvious competence, while process competence requires more thought, exploration and elaboration. Whatever the reasons, one conclusion of this study is that process competence is heavily emphasized as essential for EPCS counselors. The counseling alliance, awareness and challenging/confronting are highlighted as central factors in the EPCS's notion of process competence. Expert knowledge is perceived as important, but it was not thoroughly elaborated upon by the participants. Only two aspects were mentioned: humility regarding clients' perspectives and the significance of clients' ownership. The latter is underscored as essential but difficult to ensure. Process competence is thereby involved in one aspect of expert knowledge: how to ensure clients' ownership of relevant aspects through the dissemination of counselors' expert knowledge. The two types of competencies are united in this ownership phenomenon. Therefore, another conclusion in this study is that process competence and expert knowledge are seen as "two sides of the same coin"; both are seen as essential competencies of EPCS counselors. 
However, the categories developed in this study are in no way exhaustive with respect to significant counseling competencies. They must be seen as contributions to a larger field, and further research on counseling in special needs education contexts is necessary to establish more empirical knowledge. Future research could explore counseling sessions by combining video observation and interviews. Investigating clients' views on essential counseling competencies within a framework of special needs counseling, using both qualitative and quantitative methods, could also be of interest. Comparisons of competencies in counseling with those of teachers and parents are another topic for future research. Directly counseling students with special needs may also be addressed in future research.

One consequence of the current study concerns counselors' education/training. In accordance with the findings, the following main themes should be highlighted together: the significance of EPCS process competence and expert knowledge. How to be aware and support clients' ownership should be addressed in the training/education of counselors. Lectures on these topics, practical exercises and supervision by experienced counselors appear to be essential. 


\section{References}

Act of Education. (1998). Lov om grunnskolen og den vidaregåande opplæring. Oslo: Kunnskapsdepartementet.

Bedi, R. P., Davis, M. D., \& Williams, M. (2005). Critical incidents in the formation of the therapeutic alliance from the client's perspective. Psychotherapy: Theory, Research, Practice, Training, 42(3), 311-323. doi:http://dx.doi.org/10.1037/0033-3204.42.3.311

Bjørndal, C.R.P. (2011). Hva er kvalitet i veiledning? I T. Karlsen (Ed.) Veiledning under nye vilkår (pp 32-49). Oslo: Gyldendal Akademisk.

Bjørndal, C.R.P. (2009). Konstruktive hjelpesamtaler. Oslo: Gyldendal Akademisk forlag

Bordin, E. S. (1979). The generalizability of the psychoanalytic concept of the working alliance. Psychotherapy: Theory, Research, \& Practice, 16, 252-260. doi:http://dx.doi.org/10.1037/0033-3204.42.3.311

Bordin, E. S. (1994). Theory and research on the therapeutic working alliance: New directions. In A. O. Horvat, \& L. S. Greenberg (Eds.), The working alliance: Theory, research and practice (pp. 1337). New York: Wiley.

Cameron, D.L., Kovac, V.B., \& Tveit, A.D. (2011). En undersøkelse om PP-tjenestens arbeid med barnehagen. Skriftserie nr. 155e. Kristiansand: Universitetet i Agder.

Corbin, J. \& Strauss, A. (2008). Basics of Qualitative Research 3e. California: Sage Publications Inc.

Dalen, M. (2004). Intervju som forskningsmetode: En kvalitativ tilnærming. Oslo, Norway: Universitetsforlaget

Egan, G. (2014). The skilled helper. A problem-management and opportunity-development approach to helping. Belmont. Brooks/Cole Publishing.

Falender, C. A., \& Shafranske, E. P. (2004). Clinical supervision: A competency-based approach. Washington, D.C.: American Psychological Association.

Flückiger, C., Del Re, A. C., Wampold, B. E., Symonds, D., \& Horvath, A. O. (2012). How central is the alliance in psychotherapy? A multilevel longitudinal meta-analysis. Journal of Counseling Psychology, 59(1), 10-17. doi:http://dx.doi.org/10.1037/a0025749

Fuller, S. (2006). The constitutively social character of expertise. In E. Selinger, \& R. P. Crease (Eds.), The philosophy of expertise. New York: Colombia University Press.

Gelso, C. J., Williams, E. N., \& Fretz, B. R. (2014). Counseling psychology (3rd ed.). Washington, D.C.: American Psychological Association.

Gold, E., \& Zahm, S. (2008). The need for gestalt therapy research. In P. Brownell (Ed.), Handbook for theory, research and practice in gestalt therapy. Newcastle: Cambridge Scholars Publishing.

Haugstvedt, K. T., Graff-Iversen, S., Bukholm, I. R., Haugli, L., \& Hallberg, U. (2013). Processes of enhanced self-understanding during a counselling programme for parents of children with 
disabilities. Scandinavian Journal of Caring Sciences, 27, 108-116.

doi:http://dx.doi.org/10.1111/i.1471-6712.2012.01008.x

Hays, D. G., \& Wood, C. (2011). Infusing qualitative traditions in counseling research designs. Journal of Counseling \& Development, 89, 288-295. doi:http://dx.doi.org/10.1002/j.1556-6678.2011.tb00091.x

Horvath, A. O., \& Bedi, R. P. (2002). The alliance. In J. C. Norcross (Ed.), Psychotherapy relationships that work: Evidence-based responsiveness (pp. 365-372). New York: Oxfrod University Press.

Horvath, A. O., Del Re, A. C., Flückiger, C., \& Symonds, D. (2011). Alliance in individual psychotherapy. Psychotherapy (Chicago, III.), 48, 9-16. doi:http://dx.doi.org/10.1037/a0022186

Hustad, B.-C., Strøm, T., \& Strømsvik, C. L. (2013). Kompetanse i PP-tjenesten - Til de nye forventningene? Kartlegging av kompetansen i PP-tjenesten. NF-rapport nr. 2/2013. Bodø, Norway: Norlands Forskning [Nordland Research Institute].

Kaslow, N. J., Borden, K. A., Collins, F. L., Forrest, L., Illfelder-Kaye, J., Nelson, P. D., ... \& Willmuth, M. E. (2004). Competencies conference: Future directions in education and credentialing in professional psychology. Journal of Clinical Psychology, 60, 699-712. doi:http://dx.doi.org/10.1002/iclp.20016

Kolb, D. A. (1984). Experiential learning: Experience as the source of learning and development. New Jersey: Englewood Cliffs.

Kvale, S., \& Brinkmann, S. (2009). Interviews: Learning the craft of qualitative research interviewing. Los Angeles, CA: Sage.

Ladany, N., \& Inman, A. G. (2012). Training and supervision. In E. M. Altmaier \& J. C. Hansen (Eds.), Oxford handbook of counseling psychotherapy (pp. 179-207). New York, NY: Oxford University Press.

Lassen, L. (2014). Rådgivning. Kunsten å hjelpe og sikre vekstfremmende prosesser. Oslo: Universitetsforlaget.

Lindseth, A., \& Norberg, A. (2004). A phenomenological hermeneutical method for researching lived experience. Scandinavian Journal of Caring Sciences, 18, 145-153.

doi:http://dx.doi.org/10.1111/j.1471-6712.2004.00258.x

NESH. (2006). Forskningsetiske retningslinjer for samfunnsvitenskap, humanoria, juss og teologi. Oslo: De nasjonale forskningsetiske komiteer.

Nissen-Lie, H. A., Havik, O. E., Høglend, P. A., Monsen, J. T., \& Rønnestad, M. H. (2013). The contribution of the quality of therapists' personal lives to the development of the working alliance. Journal of Counseling Psychology, 60(4), 483-495.

doi:http://dx.doi.org/10.1037/a0033643

Nordcross, J. C., \& Lambert, M. J. (2011). Evidence-based therapy relationships. In J. C. Nordcross (Ed.), Psychotherapy relationships that work: Empirically-based responsiveness (2nd ed, pp. 3-21). New York, NY: Oxford University Press. 
Orlinsky, D. E., Grawe, K., \& Parks, B. K. (1994). Process and outcome in psychotherapy - Noch einmal. In A. E. Bergin, \& S. L. Garfield (Eds.), Handbook of psychotherapy and behavior change. New York: Wiley.

Orlinsky, D. E., Rønnestad, M. H., \& Willutzki, U. (2004). Fifty years of psychotherapy processoutcome research: Continuity and change. In M. J. Lambert (Ed.), Bergin and Garfield's handbook of psychotherapy and behavior change (5th ed) (pp. 307-389). New York: Wiley.

Perls, F., Hefferline, R. F., \& Goodman, P. (1994). Gestalt therapy: Excitement and growth in the human personality. Gouldsboro, ME: Highland Gestalt Journal Press.

Råbu, M., Halvorsen, M. S., \& Haavind, H. (2011). Early relationship struggles: A case study of alliance formation and reparation. Counselling and Psychotherapy Research, 11(1), 23-33. doi:http://dx.doi.org/10.1037/a0033643

Richards, L. (2009). Handling qualitative data: A practical guide. London: Sage Publishing House.

Rønnestad, M. H. \& Orlinsky, D. E. (2005). Aspects of Professional Development. In D. E. Orlinsky, \& M. H. Rønnestad (Eds.), How psychotherapists develop: A study of therapeutic work and professional growth. Washington D. C.: American Psychological Association.

Rogers, C. R., Kirschenbaum, H., \& Henderson, V. L. (1990). Carl Rogers: Dialogues: Conversations with Martin Buber, Paul Tillich, B.F. Skinner, Gregory Bateson, Michael Polanyi, Rollo May, and others. London, UK: Constable.

Rychen, D. S. (2009). Key competencies: Overall goals for competence development: An international and interdisciplinary perspective. In R. Maclean, \& D. Wilson (Eds.), International handbook of education for the changing world of work (pp. 2571-2583). Dordrecht, The Netherlands: Springer Science+Business Media B.V.

Schibbye, A. L. (2012). Relasjoner. Et dialektisk perspektiv på eksistensiell og psykodynamisk psykoterapi [Relatonship. A dialectic perspective at existential and psychodynamic psychotherapy]. Oslo, Norway: Universitetsforlaget.

Simon, N. S. (2009). Applying gestalt theory to coaching. Gestalt Review, 13(3), 230-240.

Usher, C. H., \& Borders, L. D. (1993). Practicing counselors' preferences for supervisory style and supervisory emphasis. Counselor Education and Supervision, 33(2), 66-79.

Watkins, Jr., C. E. (1997). Reflections on contemporary psychotherapy practice, research, and training. Journal of Contemporary Psychotherapy, 27(1), 5-22. doi:http://dx.doi.org/10.1023/A:1025664512882

Wheeler, S., \& Richards, K. (2007). The impact of clinical supervision on counsellors and therapists, their practice and their clients. A systematic review of the literature. Counselling and Psychotherapy Research, 7(1), 54-65. doi:http://dx.doi.org/10.1080/14733140601185274

Yontef, G. M., Bar-Yoseph, T. L. (2008). Dialogical Relationship. In P. Brownell (ed.), Handbook for Theory, Research, and Practice in Gestalt therapy. Newcastle: Cambridge Scholars Publishing. 